\title{
Immunohistochemical Evaluation of Chronic Endometritis by CD138, CD3 and CD20
}

\author{
Tarunpreet Kaur Sarpal ${ }^{1}$, Ranjeev Bhagat ${ }^{1 *}$, Rajpal Singh Punia ${ }^{1}$, Pavithra HN ${ }^{1}$, Bharti Goyal ${ }^{2}$ and Uma Handa ${ }^{1}$ \\ 'Pathology Dept, Govt Medical college \& Hospital sec 32 Chandigarh, India \\ ${ }^{2}$ Gyn and Obs Dept, Govt Medical college \& Hospital sec 32 Chandigarh, India
}

\begin{abstract}
Background: Chronic inflammation of endometrium is often clinically silent but may present as abnormal uterine bleeding, dyspareunia, infertility, leucorrhoea and sometimes urinary symptoms. The diagnosis is often rendered on histopathological examination of endometrial biopsy showing chronic inflammatory infiltrate in general and plasma cells in particular. In order to identify scant plasma cells and lymphocytes in the chronic endometritis, immunohistochemistry is increasing being used to confirm the diagnosis.
\end{abstract}

Aims and Objectives:To study the utility of panel of CD3, CD20 and CD 138 in the evaluation of chronic endometritis in cases of abnormal uterine bleeding and infertility and correlate the result of immunohistochemistry with routine $\mathrm{H} \& \mathrm{E}$ staining.

Method and Material: 100 consecutive cases of abnormal uterine bleeding and infertility were taken and histopathological diagnosis was made. IHC with all the three markers were applied in all the cases irrespective of histopathological diagnosis.

Results: A total of 100 cases of endometrial currettings and biopsies were studied who presented with AUB. 17 cases were diagnosed as chronic endometritis purely on histopathology while 8 additional cases were identified with help of immunohistochemistry. Two cases diagnosed on histopathology were negative on immunohistochemistry. Out of all the three markers CD 138 was the most specific while CD 3 was least specific in diagnosing chronic endometritis.

Conclusion: Immunohistochemistry particularly CD 138 is very useful in suspected cases of chronic endometritis particularly in cases where histopathology does not show any evidence of chronic inflammation.

Keywords: Endometritis, Abnormal Uterine Bleeding, Immunohistochemistry, Histopathology.

\section{Introduction}

Chronic endometritis is characterised by persistent inflammation of the endometrium. About $3-10 \%$ of patients presenting with abnormal uterine bleeding are diagnosed with chronic endometritis on endometrial biopsy. ${ }^{[1]}$ Histopathologically the lesion shows presence of stromal edema, leucocytic infiltration along with presence of plasma cells in the stromal substance. ${ }^{[2]}$ Chronic endometritis should be suspected whenever there is dyssynchronous maturation between the stroma and glands. The presence of plasma cells in the endometrial stroma is considered as diagnostic hallmark of chronic endometritis. ${ }^{[3]}$

The exact prevalence of chronic endometritis in the general population cannot be determined as the patients are usually asymptomatic. ${ }^{[4]}$ The common symptoms associated with chronic endometritis are dysmenorrhoea, dyspareunia, abnormal uterine bleeding, fever, leucorrhoea and occasionally purulent vaginal discharge. ${ }^{[5]}$

Microscopically, chronic endometritis is diagnosed based on the presence of plasma cells in the endometrium along with lymphocytes, macrophages and rarely polymorphonuclear neutrophils. The common mimickers of plasma cells in the endometrium are lymphocytes and endometrial stromal cells having an eccentric nucleus. The other morphological features which aid in the diagnosis are superficial stromal edema with increased stromal density, stromal breakdown, irregularity architecture of glands, and leucocytic infiltrate particularly lymphocytes ${ }^{[1]}$

There is variation in the leukocyte subpopulation during the normal menstrual cycle as in proliferative and early secretory phases, there is predominance of macrophages, natural killer cells and $\mathrm{T}$ cells which comprises of approximately $10 \%$ of endometrial stromal cells. However in late secretory stage, these cells comprises of $20 \%$ of the stromal cells. [6] This increase in the cellularity is because of increase in NK cell numbers as the T lymphocytes remain relatively constant throughout the menstrual cycle. ${ }^{\text {[7] }}$ On the contrary, plasma cells are very rarely seen in normal endometrial tissue, ${ }^{[8]}$ while the B lymphocytes are only sporadically identified and comprises of less than $2 \%$ of all endometrial leukocytes. ${ }^{[9]}$

There are many conditions which can create diagnostic difficulties in detecting chronic endometritis as they 
can cause obscuration of plasma cells. These include plasmacytoid stromal cells, abundant stromal mitosis, predecidual reaction, menstrual changes and exogenous progesterone effects. ${ }^{[10-12]}$. There have been a good number of studies on detection of plasma cells with CD138, but the studies based upon identification of leukocyte subpopulation on IHC are limited.

\section{Aims and Objectives}

To study the role of CD3, CD20 and CD 138 in the evaluation of chronic endometritis in cases of abnormal uterine bleeding and infertility.

Correlation of immunohistochemistry and routine haematoxylin and eosin staining in cases of chronic endometritis.

\section{Material and Method}

The present study was conducted in the Department of Pathology in collaboration with the Department of Obstetrics and Gynaecology in a tertiary care teaching hospital. The study included endometrial curetting from cases of AUB and endometrial biopsies from cases of infertility. A total of 100 cases were enrolled for the study. The specimens were processed routinely and were stained with routine $\mathrm{H} \& \mathrm{E}$ staining $^{[13]}$ and special stain wherever needed. Immunohistochemistry for CD 3, CD 20 and CD 138 was done using standard protocol used in our department.

\section{Results}

A total of 100 cases of endometrial currettings and biopsies were included in the study who presented with AUB and infertility. The patients were in the age range of 22-70 years, with mean age of $38.86 \pm 9.17$ years. All patients presented with chief complaint of abnormal uterine bleeding. In addition 25 patients presented with pelvic pain, 18 patients presented with fever, 42 with discharge per vaginum, 17 with infertility and 4 presented with complaint of dyspareunia. Two patients had past history of tuberculosis for which they had received anti-tubercular treatment. Majority of them were parous patients (most of them with para 2). There was no history of recurrent pregnancy loss in any of the patients. However, $4 / 25$ patients had history of use of intra uterine contraceptive device (IUCD).

Histopathological examination was done with 4 factors being evaluated in every case which were phase of menstrual cycle, presence or absence of plasma cells, presence or absence of granulomas and diagnosis on examination of $\mathrm{H} \& \mathrm{E}$ slides.

In current study $\mathrm{H} \& \mathrm{E}$ examination of 100 endometrial biopsies with abnormal uterine bleeding was done. Sixty biopsies were diagnosed as proliferative phase, 19 as disordered proliferative phase, 2 as secretory phase and 19 were diagnosed as chronic endometritis. Out of 19 with a diagnosis of chronic endometritis 2 were diagnosed as tuberculous endometritis and 4 were diagnosed as granulomatous endometritis on histopathological examination. (Table 1) Out of total of 100 cases, plasma cells were identified in 19 cases on $\mathrm{H} \& \mathrm{E}$ examination. Six cases out of 100 cases showed presence of granulomas along with plasma cells. Two cases were positive for AFB stain and were diagnosed as tuberculous endometritis. Rest of the 4 cases were diagnosed as granulomatous endometritis. All the 6 cases showed presence of plasma cells on $\mathrm{H} \& \mathrm{E}$ slide examination. The sensitivity and specificity of $\mathrm{H} \& \mathrm{E}$ examination in detection of plasma cells was $68 \%$ and $95 \%$.

Along with microscopic examination of $\mathrm{H} \& \mathrm{E}$ stained sections, IHC with CD 138, CD20 and CD3 were assessed simultaneously in all the 100 patients of AUB. CD138 expression (Fig .1 a \& 1b) was found in 25 cases out of 100 cases. Out of these 17 cases were diagnosed as chronic endometritis on histopathological examination. CD138 was helpful in detection of plasma cells in cases diagnosed as chronic endometritis on histopathological examination. ( $\mathrm{P}$ value $0.000,<0.05$ and statistically significant).

In 8 cases diagnosis of chronic endometritis was missed on histopathological examination and plasma cells were detected on IHC. (Fig 2a and 2b). Two cases were diagnosed as chronic endometritis on histopathological examination and on application of IHC no plasma cells were detected. The H \& E slides were reviewed, and diagnosis of secretory phase was given in these two cases.

CD20 expression was found in 22 out of 100 cases. All the 22 cases positive for CD20 were also positive for CD138. ( $\mathrm{P}$ value $0.000,<0.05$ and statistically significant) This indicates that number of B lymphocytes is increased in biopsies of chronic endometritis.

CD3 expression was positive in 83 out of 100 cases. All histopathologically proven cases of endometritis were positive for CD3. CD3 was positive in histologically normal endometrium as well in cases of chronic endometritis and hence CD3 positivity was not associated exclusively with cases of chronic endometritis ( $\mathrm{P}$ value 0.133 , > 0.05 , statistically insignificant). Overall the comparison of expression of all the $3 \mathrm{IHC}$ markers were done in both chronic endometritis versus non chronic endometritis cases (Table 2)

\section{Discussion}

The true prevalence of chronic endometritis cannot be determined as many of the patients go unnoticed as they 
Table 1: Diagnosis on H \& E examination of slides.

\begin{tabular}{|c|c|}
\hline Diagnosis on H \& E & No. of cases $(\mathbf{n}=100)$ \\
\hline Proliferative phase & $60(60 \%)$ \\
\hline Disordered proliferative phase & $19(19 \%)$ \\
\hline Chronic endometritis & $13(13 \%)$ \\
\hline Granulomatous endometritis & $04(04 \%)$ \\
\hline Tuberculous endometritis & $02(02 \%)$ \\
\hline Secretory phase & $02(02 \%)$ \\
\hline
\end{tabular}

Table 4: Distribution of CD3, CD20 and CD138 positivity in cases of chronic endometritis and other than chronic endometritis..

\begin{tabular}{|c|c|c|c|}
\hline Final Diagnosis & CD138 positivity & CD20 positivity & CD3 positivity \\
\hline $\begin{array}{c}\text { Chronic endometritis } \\
(\mathrm{n}=\mathbf{2 5})\end{array}$ & 25 & 22 & 25 \\
\hline $\begin{array}{c}\text { Other than chronic endometritis } \\
(\mathbf{n}=\mathbf{7 5})\end{array}$ & 0 & 0 & 68 \\
\hline $\mathbf{P}$ - value & $0.00(<0.05)$ & $0.00(<0.05)$ & $0.1330 .05)$ \\
\hline
\end{tabular}
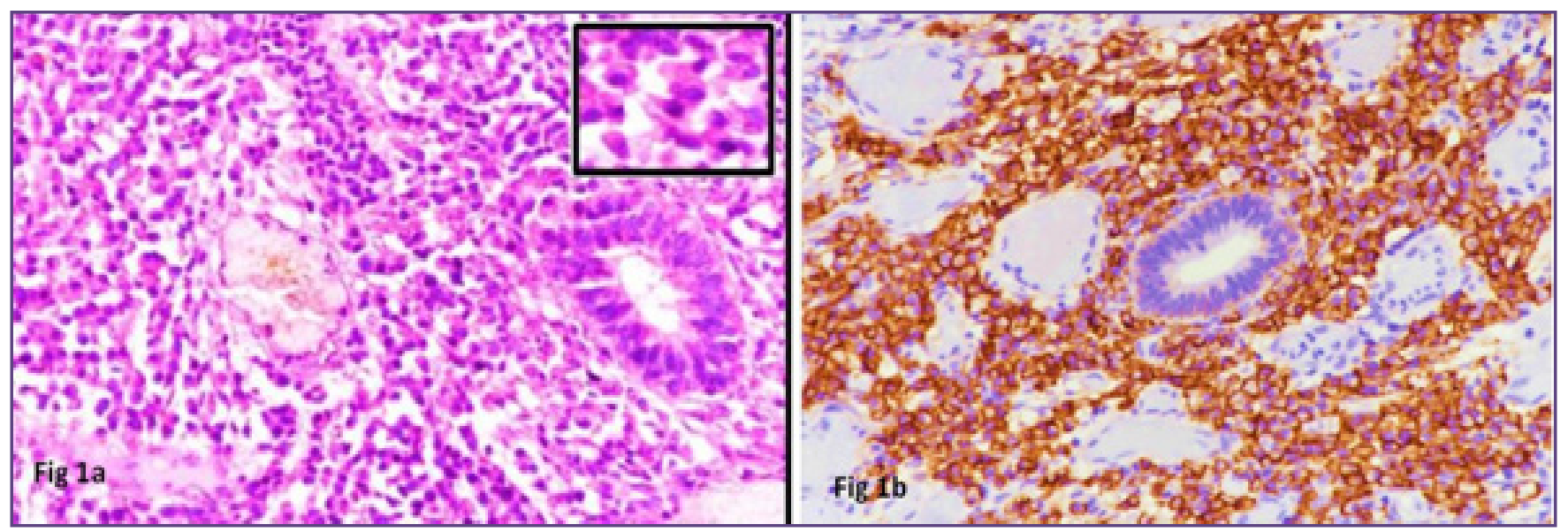

Fig. 1a: Endormetrial stroma showing plasma cells in a case of chrinic edometritis, inset highlighting plasma cells (H \& Ex400). Fig. 1b: Plasma cells highlighted by CD 138 stain (CD138x400).

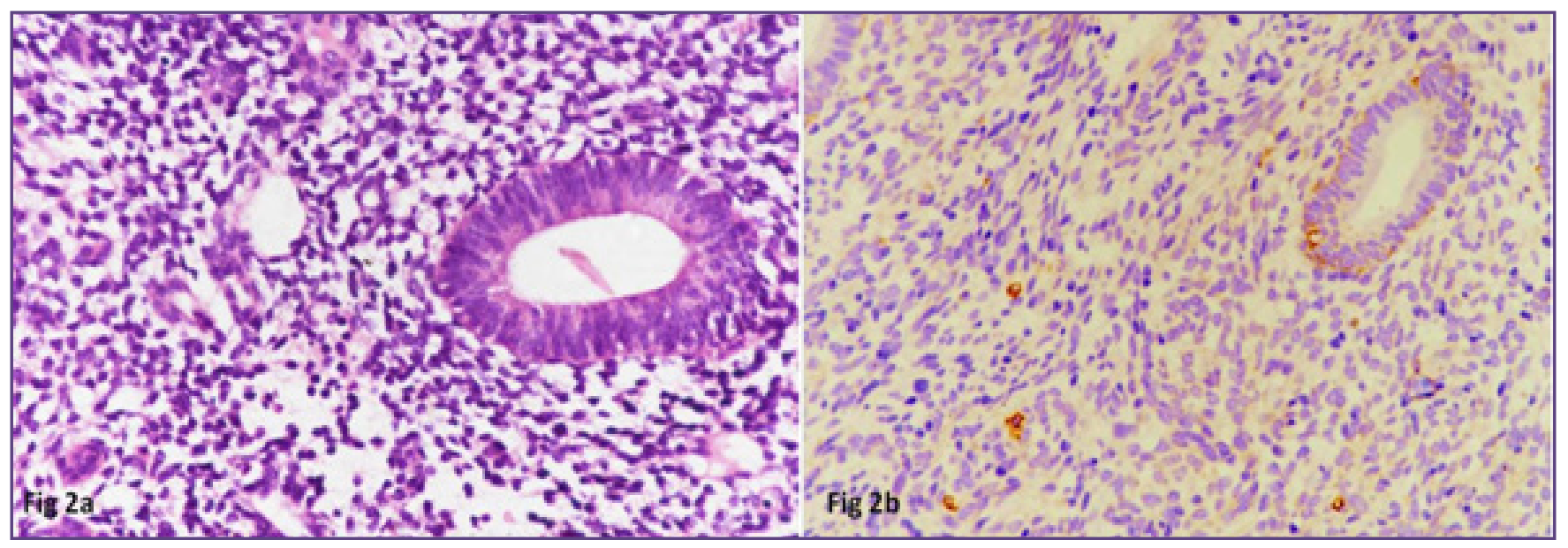

Fig. 2a: Endometrial stroma in disordered proliferative phase with absence of plasma cells (H \& E x400). Fig 2b same case with plasma cells highlighted by CD 138 (CD138x400). 
remain asymptomatic ${ }^{[4]}$ In our study, prevalence of chronic endometritis was found to be $25 \%$. A study conducted using flowcytometric detection of plasma cells found $30 \%$ cases showing presence of plasma cells in women undergoing hysterectomy for abnormal uterine bleeding. ${ }^{[14]}$ In another study conducted by Bayer - Garner et al. 43 cases were selected for immunohistochemical evaluation by CD138. 18 out of 43 cases had already been diagnosed as chronic endometritis on histopathology and the remaining $25 \mathrm{had}$ been diagnosed as abnormal uterine bleeding. This might be the reason for a high prevalence $(42.6 \%)$ in this study ${ }^{[1]}$. A study conducted by Kannar et al. ${ }^{[15]}$ the prevalence of chronic endometritis was found to be $52 \%$ which is much higher than various other studies mentioned in the literature. This high prevalence may be due to the small sample size $(\mathrm{n}=50)$ in the study.

In our study, the patients of chronic endometritis presents commonly with AUB along with other complaints like discharge per vaginum, dyspareunia, pelvic pain, infertility and fever similar to other studies. ${ }^{[16,17]}$ However, there was no significant association of any of the symptoms with chronic endometritis as compared with patients with a diagnosis other than chronic endometritis except for infertility $(\mathrm{P}$ value $<0.05)$

There were $8 / 25$ cases in whom the plasma cells or chronic endometritis was failed to be diagnosed on routine H \& E staining. Similarly a study conducted by Bayer - Garner et al. ${ }^{1}$ plasma cells were missed in 14 (20\%) endometrial biopsies on $\mathrm{H} \& \mathrm{E}$ examination out of 20 immunohistochemically confirmed chronic endometritis cases with a total of 50 biopsies under evaluation. The reason for the missed diagnosis was very few scattered plasma cells, the usual presence of plasmacytoid endometrial stromal cells, obscuration by blood or procedural artefacts. Also, at times serial sections at multiple levels may be needed to detect the collection of plasma cells.

These very few plasma cells were detected with genuine IHC marker CD138 which was applied on all the 100 cases recruited in the study. The plasma cells were present in 25 cases which showed strong positivity for CD138 along with CD20 postivity. Few other studies also support this concept. ${ }^{[1,17]} \mathrm{CD} 3$ was also performed which detected the $\mathrm{T}$ lymphocytes in the endometrial stroma. However, CD3 positive $\mathrm{T}$ cells were also present in the normal endometrial stroma which attenuates its significance in cases of endometritis.

There have been few studies carried out for immunohistochemical characterization of leucocytes in endometrium. ${ }^{[18,19]}$. In a study, endometrial tissue from 79 cases of endometritis and 22 histologically normal controls were taken. Immunohistochemical characterisation of leucocytes was done using CD45, CD20, CD68, CD3 and CD56. Increased number of leucocytes was seen in cases of chronic endometritis. Most of the cases showed substantially increase in the number of B lymphocytes, which normally represent $1 \%$ or less of the endometrial leucocyte population. ${ }^{[18]}$

In another study, 25 cases of chronic endometritis and 35 controls were investigated with antibodies CD3, CD20 and Ham 56 for T cell, B cell and macrophages respectively. CD20 positive cells comprised less than $2 \%$ of immune cells in control patients. Large numbers of CD3 and CD20 positive lymphocytes were found in cases of chronic endometritis. ${ }^{[19]}$

Similar immunohistochemical findings of leucocytic subpopulation were observed in current study also. The endometrial biopsy/curettings were evaluated for immune cells, immunohistochemically using CD3, CD20 and CD138 for T cells, B cells and plasma cells respectively. Twenty five out of 100 cases were positive for both CD138 and CD3. Out of these 25 chronic endometritis cases, 22 cases were positive for CD20. In 75 cases with a diagnosis other than chronic endometritis, 68 showed positivity for CD3 and none was positive for CD20 and CD138.

Presence of CD20 positivity was significantly associated with immunohistochemically proven cases of chronic endometritis ( $\mathrm{P}$ value $0.00,<0.05)$. However, the association of $\mathrm{CD} 3$ positivity with chronic endometritis was not significant (P value $0.133,>0.05$ ). The rate of detection of chronic endometritis by CD138 was greater than $\mathrm{H} \& \mathrm{E}$ examination of slides ( $25 \% \mathrm{vs} 17 \%$, P value $<0.05)$.

\section{Conclusion}

AUB is an important hurdle for gynecologists. Among the non-neoplastic endometral causes, chronic endometritis is an important one. Endometrial biopsy or currettings are crucial for the diagnosis. Presence of plasma cells is an important landmark for chronic endometritis. They may be subtle indicators of granulomatous endometritis or tubercular endometritis which is an important cause of infertility in tropical country like India. The plasma cells may be very few in number so that they may at times be missed on H\&E sections. Here comes the role of immunohistochemistry (CD20 and CD138) to detect these subtle cases. However, CD3 which is T cell marker may be of not much importance to detect the missed cases of chronic endometritis as the $\mathrm{T}$ cells are presence in ample amount even in the normal endometrial biopsies. Therefore, CD138 increases the rate of detection of plasma cells and hence of chronic endometritis. It is very important 
to recognize chronic endometritis because it is treatable with antibiotics or antitubercular drugs depending in the etiology as against malignancies and AUB of unknown etiology to avoid uncessary surgeries like hysterectomy.

\section{Acknowledgement}

Mrs Antu Garg and Mrs Rajni for the technical help

\section{References}

1. Bayer Garner IB, Nickell JA, Korourian S. Routine syndecan-1 immunohistochemistry aids in the diagnosis of chronic endometritis. J Arch Pathol Lab Med 2004; 128:1000-3.

2. Greenwood SM, Moran JJ. Chronic endometritis: morphologic review references and clinical observations. Obstet Gynecol 1981; 58: 176-83.

3. Crum CP, Egawa K, Fenoglio CM, Richart RM. Chronic endometritis: The role of immunohistochemistry in the detection of plasma cells. Am J Obstet Gynecol 1983;147: 812-5.

4. Farooki MA. Epidemiology and pathology of chronic endometritis. Int Surg 1967; 48: 566-73.

5. Pitsos M, Skurnick J, Heller D. Association of pathologic diagnoses with clinical findings in chronic endometritis. J Reprod Med 2009; 54:373-7.

6. Bulmer JN, Lunny DP, Hagin SV. Immunohistochemical characterization of stromal leukocytes in nonpregnant human endometrium. Am J Reprod Immunol Microbiol 1988;17: 83-90.

7. King A, Wellings V, Gardner L, Loke YW. Immunohistochemical characterization of the unusual large granular lymphocytes in human endometrium throughout the menstural cycle. Hum Immunol 1989; 24:195-205.

8. Poropatich C, Rojas M, Silverberg SG. Polymorphonuclear leukocytes in the endometrium during the normal menstrual cycle. Int J Gynecol Pathol 1987; 6:230-4.

9. Marshall RJ, Jones DB. An immunohistochemical study of lymphoid tissue in human endometrium. Int J Gynaecol Pathol 1988; 7: 225-35.
10. Andrews WW, Hauth JC, Cliver SP, Conner MG, Goldenberg RL, Goepfert AR. Association of asymptomatic bacterial vaginosis with endometrial microbial colonization and plasma cell endometritis in nonpregnant women. Am J Obstet Gynecol 2006; 195:1611-6.

11. Crum CP, Egawa K, Fenoglio CM, Richart RM. Chronic endometritis: The role of immunohistochemistry in the detection of plasma cells. Am J Obstet Gynecol 1983; 147: 812-5.

12. Bayer Garner IB, Korourian S. Plasma cell in chronic endometritis are easily identified when stained with syndecan 1. Mod Pathol 2001;14: 877-9.

13. Bancroft J, Layton C. The hematoxylins and eosin. In: Bancroft J, Layton C, Suvarna SK editors. Bancroft"s Theory and practice of histological techniques. 7 th ed. Philadelphia: Elsevier; 2013p173-86.

14. Vicetti Miguel RD, Chivukula M, Krishnamurti U, Amortegui AJ, Kant JA, Sweet RL,et al . Limitations of the criteria used to diagnose histologic endometritis in epidemiologic pelvic inflammatory disease research. Pathol Res Pract 2011; 207: 680-5.

15. Kannar V, Lingaiah HKM, Sunita V. Evaluation of endometrium for chronic endometritis by using syndecan 1 in abnormal uterine bleeding. J Lab Physicians 2012 ; 4: 69-73.

16. Kitaya $\mathrm{K}$, Yasuo $\mathrm{T}$. Immunohistochemistrical and clinicopathological characterization of chronic endometritis. Am J Reprod Immunol 2011; 66: 410-5.

17. Chen Y, Fang R, Luo Y, Luo CQ, Analysis of the diagnostic value of CD138 for chronic endometritis, the risk factors for the pathogenesis of chronic endometritis and the effect of chronic endometritis on pregnancy: A cohort study. BMC Women's Health 2016;16:60-7.

18. Disep B, Innes BA, Cochrane HR, Tijani S, Bulmer JN. Immunohistochemical characterization of endometrial leucocytes in endometritis. Histopathology 2004; 45: 625-32.

19. Tawfik O, Venuti S, Brown S, Collins J.Immunohistochemical characterisation of leukocytic subpopulations in chronc endometritis. Infect Dis Obstet Gynecol. 1996;4:287-93. 